\title{
La dimensión objetiva de los derechos fundamentales como parámetro de legitimidad material en el Estado constitucional de Derecho
}

\author{
The objective dimension of fundamental rights as a parameter of material legitimacy \\ in the Constitutional rule of law
}

\section{Catalina SALem GeSelL}

Universidad Católica de Chile

\begin{abstract}
RESUMEN El presente trabajo desarrolla el concepto de la dimensión objetiva de los derechos fundamentales y de cómo tal dimensión se erige como parámetro de legitimidad material del Estado Constitucional de Derecho. Luego, se analizan dos sentencias del Tribunal Constitucional chileno que recogen precisamente este parámetro de control respecto de: 1) la actividad del legislador; 2) como un argumento a favor del necesario control de la Justicia Constitucional; y 3) como límite de eficacia horizontal y vertical de los derechos fundamentales.
\end{abstract}

PALABRAS CLAVE Derechos fundamentales, neoconstitucionalismo, orden de valores.

\begin{abstract}
The present article seeks to develop the concept of the objective dimension of fundamental rights and how this dimension becomes a criterion of material legitimacy in the constitutional rule of law. Forward, the article analyses two Constitutional Court's decisions which endorse this criterion in relation with (1) the legislator; (2) as an argument in favor of the necessity of constitutional jurisdiction; and (3) as a limit in the efficacy of fundamental rights.
\end{abstract}

KEYWORDS Fundamental rights, neoconstitutionalism, values order.

\section{Introducción}

La dimensión objetiva de los derechos fundamentales significa concebir tales derechos como un orden objetivo de principios y valores que irradian todo el ordenamiento jurídico y que se encuentran consagrados en la parte dogmática de la Constitución. Al ser ésta norma suprema y directamente vinculante tanto para los órganos del Estado como 
para toda persona, institución o grupo, se ha erigido como el parámetro de legitimidad material en el Estado constitucional de derecho.

La premisa expuesta se enmarca dentro del proceso de constitucionalización del derecho que implica aceptar una determinada definición de Constitución, en particular, aquella que la entiende como un orden fundamental de valores, fundado en la dignidad humana como valor máximo y anterior al Estado mismo. Aceptar el carácter axiológico de la Constitución implica reconocer a los derechos fundamentales como expresiones concretas de los valores constitucionales. Ello supone que los derechos fundamentales no pueden seguir siendo concebidos como meros derechos subjetivos de garantía frente al poder del Estado. Los derechos fundamentales son, también, normas objetivas de principio o decisiones valorativas que expresan un contenido axiológico de validez universal y que, tomadas en su conjunto, dan origen a un sistema de valores que afecta no sólo el ordenamiento constitucional, sino que también el ordenamiento jurídico en su totalidad.

Lo anterior sin duda constituye una perspectiva que instaura una nueva forma de control respecto de la actividad estatal y los órganos que la ejercen. Por ello en el presente trabajo, luego de desarrollar el marco teórico descrito, se analizarán dos sentencias del Tribunal Constitucional que han recogido la dimensión objetiva de los derechos fundamentales al menos en tres sentidos: a) como un límite al legislador; b) como un argumento a favor del necesario control de la justicia constitucional; y c) como límite de eficacia horizontal y vertical de los derechos fundamentales, pues obliga a los particulares y a todos los órganos del Estado.

Finalmente se extraerán algunas conclusiones respecto del cambio de paradigma que implica el reconocimiento de la dimensión objetiva de los derechos fundamentales, para el ejercicio de las potestades estatales.

\section{La Constitución como orden de valores}

El concepto de Constitución ha experimentado una profunda evolución en el último tiempo. De ser concebida como una carta de navegación para los detentadores del poder del Estado, hoy la Carta Fundamental constituye un verdadero orden fundamental de valores que se desprende directamente de la dignidad humana y de los derechos inalienables que emanan de ella, como valor superior y anterior al Estado. De una Constitución estatista se ha avanzado, en consecuencia, hacia una Constitución humanista, que impone como eje central de todo el ordenamiento jurídico ya no al Estado, sino que a la persona y sus derechos inalienables.

Concebir a la Constitución como un orden de valores ha significado, entre otras varias consecuencias, el inicio a un fenómeno gradual que ha ido operando en los distintos sistemas jurídicos a partir de la Segunda Guerra Mundial. Dicho proceso consiste en la llamada constitucionalización del ordenamiento jurídico, definido por Guastini como «un proceso de transformación de ese ordenamiento, al término del cual éste resulta totalmente impregnado por las normas constitucionales» (en Cea, 2004: 8). En 
palabras de Comanducci: «Se trata de un proceso al término del cual el derecho es 'impregnado', 'saturado' o 'embebido' por la Constitución: un derecho constitucionalizado se caracteriza por una Constitución invasiva, que condiciona la legislación, la jurisprudencia, la doctrina y los comportamientos de los actores políticos» (Comanducci, 2009: 86).

El proceso de constitucionalización del derecho es una consecuencia directa e inmediata de concebir a la Constitución como norma suprema del ordenamiento jurídico y con vinculación directa, sin necesidad de mediación de la ley para desarrollar y aplicar sus disposiciones. Asimismo, como se adelantó, las constituciones como orden axiológico dotan de contenido o materia a las normas jurídicas de un determinado sistema, condicionándolo al contenido o sustancia de las cartas fundamentales. En otras palabras, son los valores que contienen y que se desprenden de las normas constitucionales los que impregnarán el ordenamiento jurídico, produciéndose un verdadero efecto de irradiación que se extiende de manera horizontal y vertical, obligando a los entes estatales y a los particulares por igual (Cea, 2004: 12).

Según Luís M. Cruz, concebir a la Constitución como un orden de valores constituye lo decisivo y lo novedoso del constitucionalismo contemporáneo o neoconstitucionalismo pues, precisamente, el carácter axiológico de las constituciones las dota de cualidades materiales o sustanciales que la tornan prácticamente omnicomprensivas (Cruz, 2009: 16) en toda operación de creación y aplicación del derecho. Sintetiza el citado autor la materia abordada de la siguiente manera:

De hecho, en la actualidad, es difícil concebir un problema jurídico que no encuentre alguna orientación, ya sea próxima o remota, en el texto constitucional. Y en la medida en que la Constitución se ha proyectado sobre todo el ordenamiento jurídico, contribuyendo a configurar el orden social en su conjunto, las relaciones entre legislación y jurisdicción se han modificado sustancialmente: el juicio de validez de la ley depende ahora de un juicio de conformidad con la Constitución y, en definitiva, de una cierta interpretación de la misma y de los principios constitucionales por parte de un Tribunal Constitucional (Cruz, 2009: 16).

Entender la Constitución como un orden de valores que ha transformado los ordenamientos jurídicos, con mayor o menor profundización, es consecuencia, finalmente, de la adopción de una determinada teoría acerca de lo que la Constitución es: «un orden valorativo donde los elementos estructurales del Estado obedecen a principios sustantivos que se hallan también en la base del sistema de los derechos fundamentales» (Cruz, 2009: 16).

En síntesis, el orden de valores, concretizado en cada uno de los derechos fundamentales, es hoy condición, límite o margen de todo acto, estatal o particular, constituyéndose como parámetro de control para aquellos agentes llamados primeramente a garantizar el contenido axiológico de las constituciones: los jueces en general, y en especial los tribunales constitucionales. 


\section{La dimensión objetiva de los derechos fundamentales}

El origen de la Constitución como orden de valores tiene uno de sus puntos de partida en la jurisprudencia del Tribunal Constitucional alemán (Santiago, 2008: 134). Como expone Cruz, en la sentencia Lüth de 1958, el Tribunal alemán estableció los conceptos centrales de valor, ordenamiento valorativo, jerarquía valorativa y sistema de valores, sobre los cuales se apoyó en decisiones posteriores (Cruz, 2009: 17). En la sentencia referida, el Tribunal Constitucional alemán sostuvo que la Ley Fundamental no pretende ser ningún orden neutral de valores, pues:

en sus artículos sobre derechos fundamentales ha erigido un orden objetivo de valores que se manifiesta en un esfuerzo fundamental de la pretensión de validez de los derechos fundamentales. Este sistema de valores, que encuentra su núcleo esencial en la personalidad humana desarrollada libremente dentro de la comunidad social y en su dignidad, debe ser válido como fundamento jurídico-constitucional para todas las áreas del derecho: la legislación, la administración y la judicatura reciben de él pautas e impulsos (Cruz, 2009: 18).

Los valores que informan una determinada Constitución tienen su expresión concreta en los derechos fundamentales contenidos en su parte dogmática, los cuales se transforman en el «eje central del sistema [...] irradiando sus efectos sobre todas las demás normas e instituciones jurídicas» (Cea, 2004: 9). Es decir, en el proceso de constitucionalización del derecho que ya hemos explicado, los derechos fundamentales son la verdadera columna vertebral del ordenamiento jurídico, y el parámetro concreto y específico de legitimidad de las actuaciones de los órganos estatales y de los particulares: «cabe destacar la centralidad que los derechos fundamentales o derechos humanos comienzan a tener en la vida jurídica y política. Pasan a ser considerados como valores que impregnan todo el ordenamiento político-jurídico del Estado y extienden, también, su influjo a las relaciones privadas» (Santiago, 2008: 136).

Lo dicho hasta ahora significa que, hoy en día, los derechos fundamentales tienen un carácter dual: ya no sólo es posible concebir en ellos una dimensión subjetiva como derechos de defensa que se erigen como garantías para su titular frente a las acciones del Estado y de su entorno social (Vargas, 2003: 207), sino que el constitucionalismo contemporáneo reconoce igualmente en ellos una dimensión objetiva, consistente en considerar a los derechos fundamentales como:

un orden objetivo de principios y valores que irradian todo el ordenamiento jurídico y que demandan del Estado emprender un conjunto de actividades administrativas y legislativas encaminadas a cumplir, en palabras de Robert Alexy, con unos mandatos de optimización y con unos deberes de protección en materia de derechos fundamentales. Böckenforde señala, de igual manera, que en su dimensión objetiva los derechos fundamentales constituyen mandatos de acción y deberes de protección en cabeza del Estado, de suerte tal que aquéllos, en tanto que decisiones axiológicas jurídico- 
objetivas, suministran unas pautas de orientación y unos fines y objetivos a alcanzar mediante el ejercicio de las labores legislativa, ejecutiva y judicial (Vargas, 2003: 207).

A la luz de lo anterior podemos afirmar con propiedad que el reconocimiento de la dimensión objetiva de los derechos fundamentales ha implicado una nueva profundización del Estado de derecho que ha significado su rematerialización. El Estado juez y gendarme por el cual abogaba el liberalismo, y el Estado social de derecho como «estructurador de la sociedad» para garantizar la igualdad material de sus integrantes, encuentran en el Estado constitucional de derecho el mandato imperativo de realización de los derechos fundamentales, tanto ellos digan relación con los derechos políticos y civiles clásicos, como aquellos de carácter social.

De ahí que exista no sólo una obligación del Estado de abstenerse de injerencias en el ámbito que aquéllos protegen, sino también la obligación, en este caso positiva, de llevar a cabo aquello que sirva a la realización de los derechos fundamentales, incluso cuando no conste una pretensión subjetiva de los ciudadanos (Cruz, 2009: 18).

\section{La Constitución como orden de valores y el rol de los jueces}

La nueva concepción de lo que una Constitución es ha implicado un retroceso del rol del legislador, sobre todo aquel que le atribuyera Rousseau al caracterizar la voluntad soberana como infalible. Hoy los parlamentos se encuentran igualmente vinculados al orden superior de valores consagrado en las normas constitucionales, lo que nos permite afirmar con certeza que el ejercicio de los derechos fundamentales ya no depende de la permisión de la ley, sino que la ley vale en la medida en que respeta los derechos fundamentales (Cea, 2004: 7). Detrás de cada precepto legal se adivina siempre una norma constitucional que lo confirma o lo contradice (Prieto, 2007: 216).

Como contrapartida al rol mermado de la rama legislativa - en comparación con etapas históricas anteriores-, es posible constatar en la actualidad un avance en rol de los jueces, transformándose en uno de carácter activo: los jueces ya no son meros moduladores de las palabras de la ley, como sostenía Montesquieu. Este nuevo rol ha dado lugar a una serie de críticas respecto de la labor de la judicatura, en especial, de la judicatura constitucional. De allí que hoy se hable de un verdadero activismo judicial, esto es, que los jueces se valen «del poder que les confiere el derecho para, a partir de sus sentencias, poner en práctica una agenda política que tiene como norte el cambio social» (Campos, 2012: 309). Este problema precisamente encuentra una de sus raíces en la textura abierta que tienen las constituciones -impregnada de principios y valores-, lo que lleva, como señala Sager, a que el conflicto constitucional se defina en términos de que cualquier alegación sobre la vulneración de la Constitución por una decisión pública tiene un fundamento plausible en la misma Constitución, ya que en cada caso la Carta Política no corrobora claramente la validez de la alegación. Concluye que «el texto y el contexto de la Constitución ponen cada una de estas cuestiones en la agenda 
del juez. Pero, por sí solos, texto y contexto no resuelven ninguna de ellas» (Sager, 2007: 64). Así, expone que los jueces constitucionales tendrían una misión singular y redundante al mismo tiempo. Singular, porque los jueces constitucionales deben identificar los fundamentos de la justicia política que son importantes y perdurables en el régimen constitucional y controlar la legislación u otros actos gubernamentales a la luz de esos estándares. Y, por otra parte, tal labor sería redundante, pues los jueces constitucionales intervienen únicamente después de que los propios legisladores han considerado las consecuencias constitucionales de las opciones planteadas (Sager, 2007: 202).

Estas prevenciones sobre la labor de los jueces resultan relevantes al momento de identificar y lograr un acuerdo dentro del órgano colegiado sobre cuáles son los valores que consagra una determinada disposición constitucional, y, en especial, cómo esos valores se erigen como dimensión objetiva de los derechos fundamentales. La identificación de esos valores constituye un ejercicio hermenéutico que el juez debe aplicar en todos los casos que debe resolver, y si la Constitución no entrega una respuesta única y clara, el juez podría recurrir a creencias e intuiciones que pueden tener un tinte político (Posner, 2008: 96-97). De allí que Zagrebelsky afirme que los jueces deben ser independientes de sí mismos - y no sólo de otros-, para lo cual, al asumir el cargo, juran fidelidad a la Constitución. «Todas las otras fidelidades, desde ese momento en adelante, deben ceder ante ésta» (Zagrebelsky, 2008: 80). Pero reconoce que, si bien sobre la Constitución no se vota, sí las cortes constitucionales votan sobre la interpretación de la Constitución y aquí, recogiendo la crítica de Carl Schmitt, concuerda en el peligro de la politización de la justicia constitucional, en especial «cuando se someten a votación las cuestiones constitucionales y pueden formarse sobre ellas mayorías y minorías, como en las asambleas parlamentarias» (Zagrebelsky, 2008: 34-36). No resulta baladí entonces el cambio de paradigma que ha significado el Estado constitucional de derecho y el debilitamiento que ha supuesto para el rol del legislador, en especial cuando éste hace su propia interpretación y actualización de los valores constitucionales y luego es controvertida por el juez constitucional. ${ }^{1}$

Sin perjuicio de estas aprensiones, lo cierto es que los tribunales constitucionales, luego de la segunda mitad del siglo XX, han surgido como órganos que han venido a enriquecer el sistema de frenos y contrapesos en el Estado de derecho. Como nos recuerda Bachof, estos tribunales especiales son los principales guardianes de la Constitución y, en consecuencia, guardianes de ese orden de valores que ella consagra (Cruz, 2009: 21).

1. A modo ejemplar, se puede mencionar la controversia que ha surgido entre el Senado y el Tribunal Constitucional luego de que este último órgano declarare inaplicable en sucesivos casos preceptos legales de la denominada «Ley Emilia» (Ley 20.770). Al declarar inaplicable por inconstitucional el artículo 196 ter de la Ley 18.290 de Tránsito, relativo a la prohibición de aplicar una pena sustitutiva por el plazo de un año, período en el cual el condenado debe cumplir en forma efectiva la pena privativa de libertad, por resultar desproporcional (sentencias de Tribunal Constitucional roles 2936-15 y 2983-16, del 20 de octubre de 2016 y del 13 de diciembre de 2016, respectivamente), el Tribunal generó una reacción adversa del Senado, órgano que defendió la autonomía constitucional del legislador para diseñar una política criminal determinada (Boletín 1.934-12). 
La principal función de los tribunales constitucionales es controlar la conformidad de las leyes y, en ocasiones, de otros actos y decisiones emanados de órganos públicos, con la Constitución (Cappelleti, 2004: 307). En consecuencia, dentro del nuevo paradigma del Estado constitucional de derecho, corresponde a los tribunales constitucionales controlar la legitimidad material, particularmente de los actos del legislador. Esto último significa que, respecto de una ley, hoy ya no es suficiente la validez formal de la misma, sino que además se requiere que el contenido - la sustancia de esa ley-esté imbuido o, a al menos, sea concordante -y nunca opuesto- con el carácter axiológico de la Constitución. Ese es el parámetro conforme al cual los tribunales constitucionales ejercerán el control de las leyes.

\section{Dos sentencias del Tribunal Constitucional chileno}

En nuestra jurisprudencia constitucional es posible encontrar dos sentencias que precisamente concretizan y aplican los conceptos teóricos que hemos venido desarrollando. ${ }^{2}$ En efecto, con ocasión de un requerimiento de inaplicabilidad por inconstitucionalidad, del 4 de enero del año 2011, el Tribunal Constitucional chileno tuvo que pronunciarse sobre los posibles efectos inconstitucionales de la aplicación del artículo 365 del Código Penal, norma que tipifica como delito la sodomía en menores de dieciocho años (sentencia 1683-2010 del Tribunal Constitucional). El requirente, Pablo Ardouin Bórquez, defensor penal público del imputado, Jorge Washington Sepúlveda Álvarez, adujo en sede constitucional que el precepto legal citado vulneraba la dignidad, el principio de igualdad ante la ley y de no discriminación arbitraria, la libertad, el derecho a la vida privada y a la intimidad, y el contenido esencial de todos estos derechos, además de la infracción de normas contenidas en diversos tratados internacionales sobre derechos humanos. El argumento central del requirente, en resumidas cuentas, era que el precepto legal atentaba contra la libertad para sostener una relación homosexual consentida y libre con un menor de 18 años y mayor de 14, reprimiendo a una minoría que, además, se veía discriminada frente a otras relaciones sexuales, como la homosexualidad entre mujeres o incluso entre relaciones heterosexuales que implicaran también la participación de un menor de edad. Todo lo anterior, a juicio del requirente, constituía, además, una intromisión en la vida privada e intimidad de los sujetos involucrados.

Haciendo suyo el argumento del actor, en el sentido de que la revisión del mérito legislativo de la norma no inhibía al Tribunal Constitucional para resolver si los actos se ajustaban o no a la Constitución, la Magistratura Constitucional concordó en que resultaba necesario pronunciarse acerca de la plausibilidad de las razones que se tuvieron en cuenta para dar el trato diferenciado alegado en el libelo, pues ello implicaba que el Tribunal asumiera la defensa de la Carta Fundamental que se le ha encomendado incluso respecto de la ley, que sólo manifiesta la voluntad soberana cuando respeta la

\footnotetext{
2. No obstante, existe un comentario de jurisprudencia previo de Aguilar (2012) sobre otra sentencia, que es abordada de manera similar.
} 
supremacía constitucional (considerando decimoctavo). El Tribunal recordó su propia jurisprudencia en este sentido afirmando que, efectivamente, no le corresponde inmiscuirse en la esencia del ejercicio de la función pública que le corresponde al Congreso Nacional, pero ello es así mientras éste no vulnere los límites constitucionales, excediendo el ámbito de su competencia. En el considerando siguiente, el Tribunal definió precisamente cuáles son esos límites que impone la Constitución al legislador:

Vigésimo: Que los márgenes constitucionales a que se ha aludido antes dicen relación, básicamente, con los derechos fundamentales que la Constitución asegura a todas las personas, ya no sólo desde un punto de vista subjetivo, mirado desde la perspectiva del titular del derecho, sino que también desde un prisma objetivo que supone aceptar que tales derechos constituyen hoy la piedra angular de todo el ordenamiento jurídico positivo.

Así el Tribunal, basándose en el prisma objetivo de los derechos fundamentales, circunscribió precisamente el conflicto de constitucionalidad a determinar si el delito de sodomía tipificado en el artículo 365 del Código Penal podía importar, en su aplicación al caso concreto de que se trata, una vulneración de los derechos fundamentales invocados por el requirente, agregando en su considerando vigésimo segundo lo siguiente:

Esta forma de proceder no vulnera, por lo dicho, el respeto al mérito inherente a las decisiones que adopta el legislador ni a las decisiones de política criminal que le son privativas, sino que sólo constituye una expresión del mecanismo de los checks and balances que son indispensables en un Estado de derecho.

Como se aprecia, el Tribunal Constitucional chileno recogió precisamente la dimensión objetiva de los derechos fundamentales, consecuencia de concebir la Constitución como un orden fundamental de valores, y asumiendo su rol de garante de la Constitución, cuyo carácter vinculante obliga incluso al legislador en el Estado constitucional de derecho. En este contexto, para decidir el fondo del asunto, la sentencia discurrió precisamente en determinar si el acto del legislador - artículo 365 del Código Penal- superaba los límites constitucionales circunscritos por el contenido de cada uno de los derechos fundamentales que se estimaron vulnerados, para arribar a la conclusión de que no hubo un exceso de competencia legislativa, sino que todo lo contrario, pues el legislador tuvo por fin claro y preciso la protección de la indemnidad sexual de los menores de edad y su desarrollo psicosocial, lo cual dice relación con el valor de la dignidad humana de los mismos menores y de los derechos inalienables que emanan de ella.

Este fallo resulta muy pedagógico y de la mayor relevancia para entregar una ilustración práctica de la dimensión objetiva de los derechos como límite a la actividad del legislador. En esta ocasión, la identificación de la dimensión objetiva de los derechos fundamentales hecha por el Tribunal coincidió plenamente con aquella contemplada por el legislador. Lo mismo sucede con la sentencia que analizamos a continuación. Pero la cuestión queda abierta en relación a decisiones futuras del Tribunal basadas en 
esta doctrina, la cual podría llevarlo a extralimitarse en los términos revisados en el acápite anterior.

Un segundo fallo del Tribunal Constitucional que viene al caso comentar es aquella sentencia que se pronunció sobre un requerimiento de inaplicabilidad por inconstitucionalidad en contra del artículo único letra a) núm. 1 de la Ley 20.238, que agregó una oración final al inciso primero del artículo 4 de la Ley 19.886, de bases sobre contratos administrativos de suministro y prestación de servicios (sentencia 1968-2011 de Tribunal Constitucional), el cual, en síntesis, excluía del Registro Electrónico Oficial de Contratistas de la Administración del Estado al oferente o proponente en el marco de una licitación pública, privada o de contratación directa, que haya sido condenado por prácticas antisindicales o infracción a los derechos fundamentales del trabajador, dentro de los dos años anteriores. El requirente era una empresa que había resultado excluida del Registro debido a una condenada en sede de tutela laboral por infracción a los derechos fundamentales de sus trabajadores, en concreto, por el despido injustificado -calificado como represalia por el tribunal laboral- de un trabajador. Alegó en estrados que el precepto legal cuya inaplicabilidad solicitaba, vulneraba su derecho a no ser discriminado en materia económica por el Estado y sus organismos, su derecho a la igualdad ante ley, a un debido proceso y al principio de non bis in idem, pues ya había recibido una sanción por su conducta en sede laboral.

Al igual que en el fallo anterior, el Tribunal entró a dilucidar el fin de la norma perseguido por el legislador acudiendo a su historia legislativa, y concluyendo que dicho fin dice relación con el objetivo del precepto legal de proteger más eficazmente los derechos fundamentales de los trabajadores, tanto específicos como inespecíficos, agregando:

Lo anterior acorde al hecho de que, hoy en día, los derechos fundamentales no sólo tienen una dimensión subjetiva, sino que también una naturaleza objetiva que los erige en la columna vertebral del ordenamiento jurídico positivo.

Por lo demás, lo que se viene explicando resulta perfectamente acorde al deber que el artículo 5, inciso segundo, de la Carta Fundamental impone a los órganos del Estado en el sentido de respetar y promover los derechos esenciales que emanan de la naturaleza humana, garantizados tanto por la Constitución Política como por los tratados internacionales ratificados por Chile y que se encuentran vigentes (sentencia 1968-2011 del Tribunal Constitucional, considerando vigésimo noveno).

El Tribunal justificó, entonces, la validez sustantiva de la norma impugnada por el requirente sosteniendo, en otras palabras, que ésta concretiza el mandato de eficacia de los derechos fundamentales, por una parte, y que ello se debe precisamente a que éstos, como ejes del sistema jurídico, obligan a todos los órganos del Estado, entre ellos, al propio legislador. Atendido ese parámetro de control de legitimidad de la norma, el Tribunal concluye que el precepto legal resulta idóneo al fin perseguido.

En otra línea de razonamiento dentro de la misma sentencia, la Magistratura Constitucional reconoció, además, la efectividad horizontal de los derechos fundamentales al sostener que: 
debe tenerse presente que ninguna empresa que cuenta con trabajadores puede desconocer el deber de respetar integralmente los derechos de éstos, quedando sometida a las consecuencias que deriven del incumplimiento de ese deber jurídico que, a la vez, representa un imperativo ético (considerando trigésimo cuarto).

Por último, no puede dejar de mencionarse respecto de este fallo que el Tribunal Constitucional reconoció como fundamento de la inhabilidad para contratar con la Administración del Estado, prevista en el precepto legal impugnado, la falta de idoneidad en que incurre una persona natural o jurídica que, estando inscrita en el Registro Oficial de Contratistas de la Administración, infringe derechos fundamentales de sus trabajadores, así declarado por una sentencia judicial ejecutoriada (considerando cuadragésimo tercero). Lo anterior por supuesto que reafirma todo lo que hemos sostenido a lo largo de este trabajo, pues si los derechos fundamentales, en su dimensión objetiva, implican una obligación positiva del Estado, y también de los particulares, de llevar a cabo aquello que sirva a la realización de los derechos fundamentales (Cruz, 2009: 18), significa necesariamente que, por una parte, no se validen vulneraciones a los derechos fundamentales $y$, por la otra, que esas vulneraciones se proscriban y se castiguen por el ordenamiento jurídico positivo.

\section{Conclusión}

La dimensión objetiva de los derechos fundamentales significa concebir tales derechos como un orden objetivo de principios y valores que irradian todo el ordenamiento jurídico y que se encuentran consagrados en la parte dogmática de la Constitución. Al ser ésta norma suprema y directamente vinculante tanto para los órganos del Estado, como para toda persona o grupo, se ha erigido como el parámetro de legitimidad material en el Estado constitucional de derecho.

Lo anterior fue corroborado a partir del análisis de dos sentencias del Tribunal Constitucional chileno, que recogieron la dimensión objetiva de los derechos fundamentales en tres sentidos: a) como un límite al legislador; b) como un argumento a favor del necesario control de la justicia constitucional, como garante de la Constitución y por ende de su contenido axiológico; y c) como límite de eficacia horizontal y vertical de los derechos fundamentales, pues obliga a los particulares y a todos los órganos del Estado.

\section{Referencias}

Aguilar, Gonzalo (2012). «Los derechos humanos y el orden objetivo de valores como parámetro de control: la posición del voto por acoger. Comentario a la sentencia del Tribunal Constitucional que recae sobre las normas que permiten modificar unilateralmente el precio base del plan de salud». Estudios Constitucionales, 12 (1): 527-566 DOI: 10.4067/So718-52002014000100014. 
CAmpos, Heber (2012). «El activismo judicial y el constitucionalismo del futuro». En Heber Campos (editor), Control constitucional y activismo judicial. Lima: Ara Editores.

Cappelleti, Mauro (2004). «Necesidad y legitimidad de la justicia constitucional». En Mauro Cappelletti, Obras. La Justicia Constitucional. Dimensiones de la justicia en el mundo contemporáneo. México: Editorial Porrúa.

CEA, José Luis (2004). Visión del Estado constitucional de derecho. Número 29. Santiago: Cuadernos del Tribunal Constitucional.

Comanducci, Paolo (2009). Positivismo jurídico y neoconstitucionalismo. Madrid: Fundación Coloquio Jurídico Europeo.

Cruz, Luis (2009). «La Constitución como orden de valores. Reflexiones en torno al neoconstitucionalismo». Díkaion, 23 (18): 12-31. Disponible en http://bit. ly/2goenWC.

Posner, Richard (2008). Cómo deciden los jueces. Madrid: Marcial Pons.

Prieto, Luis (2007). «El constitucionalismo de los derechos». En Miguel Carbonell (editor), Teoría del neoconstitucionalismo. Madrid: Trotta.

SAGER, Lawrance (2007). Juez y democracia. Madrid: Marcial Pons.

Santiago, Alfonso (2008). «Sistema jurídico, teoría del derecho y rol de los jueces: Las novedades del neoconstitucionalismo». Díkaion, 22 (17): 132-155. Disponible en http://bit.ly/2vo6SWs.

VARGAS, Clara (2003). «La garantía de la dimensión objetiva de los derechos fundamentales y labor del juez constitucional colombiano en sede de acción de tutela: El llamado 'estado de cosas inconstitucional». Revista del Centro de Estudios Constitucionales (Universidad de Talca), 1 (1): 203-228.

Zagrebelsky, Gustavo (2008). Principios y votos. Madrid: Trotta.

\section{Sobre la autora}

Catalina Salem Gesell es abogada y magíster en Derecho LLM, mención Derecho Constitucional, de la Pontificia Universidad Católica de Chile. Profesora de Derecho Político y Constitucional del Departamento de Derecho Público de la Facultad de Derecho de la Pontificia Universidad Católica de Chile. Su correo electrónico es cesalem@ uc.cl. 
